\title{
O MONSTRO DORME NAS CAVERNAS: UMA (RE)LEITURA CONTEMPORÂNEA DO LOBISOMEM
}

Karla Menezes Lopes Niels (UFF)

Resumo: A figura do monstro, segundo Julio Jeha (2007), é a corporificação de todos nossos medos e males e, conforme já afirmara Montaigne (1991), o medo do desconhecido é o maior deles. Um sentimento que se não nos imobiliza, nos permite voar nas asas da imaginação. Assim, o monstro na narrativa ficcional corporifica o medo de um mal que não se pode compreender porque é um mistério indecifrável, impenetrável. Daí o surgimento na narrativa gótica e sua apropriação pelos textos fantásticos subsequentes da figura do vampiro, da lenda mitológica do lobisomem, dos monstros indescritíveis como o Cthulhu, de Lovecraft, da figura do duplo. Seja físico, metafísico ou moral, o monstro e o medo que sua deflagração na narrativa provoca podem ser considerados, como postula David Roas (2012), a própria essência do gênero fantástico. O horror ficcional oriundo desse tipo de literatura pode amenizar, momentaneamente, nossos horrores mais profundos ao mesmo tempo que desestabiliza a nossa sólida concepção de real frente a contemplação da representação do impossível: o ser eterno, a metamorfose, o horrífico e o tétrico. Diante disso, e a partir da consideração da figura do monstro, de suas características e de sua configuração da narrativa pós-moderna que propomos neste trabalho a análise do conto "Alguém dorme nas cavernas", de Rubens Figueiredo. Palavras-chave: Lobisomem; Fantástico; Literatura Contemporânea; Rubens Figueiredo.

Resumen: La figura del monstruo, según Julio Jeha (2007), es la encarnación de todos nuestros temores y males y, como ya se dijo Montaigne (1991), el miedo a lo desconocido es el más grande. Un sentimiento que nos inmobiliza no nos permite volar en las alas de la imaginación. Por lo tanto, el monstruo en la narrativa de ficción encarna el miedo de un mal que no puede entender por qué es indescifrable, misterio impenetrable. De ahí el surgimiento de la narrativa gótica y su posterior apropiación por parte de la fantástica cifra de los textos de vampiros, la leyenda mitológica del hombre lobo, los monstruos indescriptibles como Cthulhu, Lovecraft, la figura del doble. Si, 
monstruo metafísico o moral físico y el miedo que hace que su brote en la narración se pueden considerar como postula David Roas (2012), la esencia misma del género fantástico. La literatura de terror de ficción alcanzado la mayoría de este tipo nos da una resolución momentánea, que suaviza, por un corto tiempo, nuestros horrores más profundos, mientras que la desestabilización de nuestra concepción sólida de la real contra la contemplación de la representación de lo imposible: el ser eterno, metamorfosis, el horrible y espeluznante. Teniendo en cuenta esto, y de la consideración de la figura del monstruo, la configuración de las características de la narrativa posmoderna nos proponemos en este trabajo el análisis de la historia corta "Alguém dorme nas cavernas", de Rubens Figueiredo.

Palabras-clave: Hombre lobo; Fantástico; Literatura Contemporánea; Rubens Figueiredo.

\section{O MONSTRO}

A figura do monstro, segundo Julio Jeha (2007), é a corporificação de todos nossos medos e males e, conforme já afirmara Montaigne (1991), o medo do desconhecido é o maior deles. Um sentimento que, se não nos imobiliza, nos permite voar nas asas da imaginação. Assim é o medo do mal.

O monstro na narrativa ficcional corporifica esse tipo de medo; o medo de um mal que não se pode compreender porque é um mistério indecifrável, impenetrável; algo que "nenhum pensamento consegue objetivar" (JEHA, 2007, p.7). Pode-se, sim, através da literatura, falar dele, do mal, e pintar-Ihe um esboço mal feito de seu retrato. Um esboço daquilo que imaginamos ser o mal, mas que nunca será retrato fidedigno seu. 
Filósofos, teólogos, psicanalistas falharam ao tentar compreender e representar o mal. Fala-se de seus efeitos como se dele falasse. Por isso, conforme nos mostra o mesmo Jeha, criamos através do texto ficcional "referências metafóricas, relacionando um ser ou um acontecimento a algo que existe em um plano diferente" (2007, p.19). Criamos um quadro mental pictórico que assoma às palavras e eleva a imaginação humana à contemplação de algo jamais visto pelo homem, mas que, ao menos no plano do discurso, fazse presente, fazendo até mesmo com que o leitor aceite a possibilidade de que aquele ser, às vezes indescritivel, com que se depara no texto possa residir em seu mundo. 0 monstro pode estar ao seu lado ou ser ele mesmo.

Como maravilhas do discurso, as metáforas têm sua contraparte nos monstros, as maravilhas da natureza. "Algo monstruoso espreita" dentro das metáforas, diz Paul de Man. As metáforas podem parecer perigosas até monstruosas, porque "são capazes de inventar as entidades mais fantásticas por causa do poder posicional inerente à linguagem. Elas podem desmembrar a tessitura da realidade e entrelaça-la de novo de maneiras as mais caprichosas, emparelhando homem e mulher ou ser humano com fera, nas formas mais antinaturais". Daí a adequação de monstros e metáforas para representar o mal. (JEHA, 2007, p.19) 
Jeffrey Jerome Cohen considera que os monstros, reais ou literários, como o vampiro, o lobisomem ou mesmo o Cthulhu, de Lovecraft, são engendrados a partir dos medos do homem de uma determinada época e cultura. Trata-se da "corporificação de um certo momento cultural" (2000, p.23-60) que guarda consigo medos ocultos de um mal irrepresentável, mas real. O monstro representa, portanto, os medos internalizados de uma comunidade. Medos que podem perpassar épocas e culturas permitindo que seus monstros sobrevivam para nascer e renascer outra vez assombrando gerações a fio. Isso porque o monstro habita "o intervalo entre o momento da convulsão que o criou e o momento no qual ele é recebido - para nascer outra vez" (COHEN, 2000, p.23-60) em outra época, em outra cultura.

Por exemplo, numa de suas teses, Cohen postula que "o monstro é a diferença feita carne, um constructo da alteridade que habita entre nós." (2000, p.23-60). Seria ele a exageração da aberração cultural, social ou mesmo natural que tornase monstruosa. É o caso da descrição dos cananeus bíblicos, dos mouros na França medieval ou a dos judeus na Alemanha nazista. Descrições que deram à luz monstros que justificaram massacres e genocídios.

A própria história torna-se, um monstro: desfigurante, autodesconstrutiva, sempre 
sob o risco de expor as suturas que mantêm costurados seus separados elementos em um corpo único e pouco natural. (COHEN, 2000, p.23-60)

O homem tende a criar seus monstros a partir da diferença, pois, é ela, a diferença, que gera o medo do outro, do mal que eu acho que o outro pode me fazer ou trazer.

Mas não é só de alteridades que vivem os monstros, eles habitam também o espaço do proibido, do impenetrável, do inviolável. O mal nem sempre vem do outro, mas pode vir de mim mesmo. Daí, monstros como o vampiro que exploram a sexualidade e mostram ao homem os riscos de cruzar os muros da proibição. Tanto o monstro como a monstruosidade constituem-se "um estratagema para rotular tudo o que infringe esses limites culturais" (JEHA, 2007, p.20) através de uma narrativa que representa a repulsão de uma época e cultura a determinado comportamento considerado perigoso. Assim, esse segundo tipo de monstro, seja dentro ou fora da literatura, funciona como um "mantenedor das regras sociais".

O monstro e a metáfora têm o poder de revelar ao homem o que lhe acontecerá ao cruzar as barreiras do socialmente aceitável para determinada época e cultura. A monstruosidade se imiscui à narrativa na tentativa de 
chamar atenção "para aqueles comportamentos e atitudes que o texto está preocupado em interditar" (COHEN, 2000, p.23-60). Trata-se, portanto, de uma pedagogia do mal ou nas palavras de Cohen, uma pedagogia dos monstros que ensina ao homem a não violar as regras sociais que fazem dele um ser humano.

\section{O LOBISOMEM}

O lobisomem é um desses monstros que corporificam nossos medos e males. Mas principalmente o medo que o homem tem de si próprio, da sua sexualidade, da sua animosidade, enfim, da besta que reside dentro de si. São esses os medos corporificados por esse monstro. Um ser racional e coerente metamorfoseado numa fera é algo aterrorizador. Transformado em fera o homem não só perde a sua sociabilidade como o controle sobre suas ações; não é mais racional, age por instinto. Deixa de ser homem para ser somente lobo, mesmo que ainda mantenha resquícios de sua consciência humana.

O lobo, visto como símbolo, pode ser tanto a figura sedutora masculina, como também as tendências animalescas que jazem dentro de todo ser humano; enquanto símbolo ele é múltiplo podendo representar tanto o mal quanto o bem (RAPUCCI, 2012, p.102-103). Mas e que dizer da 
metamorfose? Da possibilidade do impossível? O lobisomem é um ser misto; não é mais homem, tampouco, animal. O que é ele então? Como compreender tal monstro?

Entendemos que trata-se de um ser que

resiste a qualquer classificação
construída com base em uma hierarquia
ou em uma oposição meramente binária,
exigindo, em vez disso, um "sistema"
que permita a polifonia, a reação mista
(diferença na mesmice, repulsão na
atração) e a resistência à integração -
eu permita que aquilo que Hogle (1988,
p.161) chamou de um jogo mais profundo
de diferenças, um polimorfismo não-
binário na base da natureza humana.
(COHEN, 2000, p.23-60)

Diante de tal ser, que não é nem lobo nem homem, “a análise científica e sua ordenada racionalidade se desintegram." (COHEN, 2000, p.23-60). Isso é ameaçador! A conflagração do lobisomem na narrativa gera uma contradição entre o natural e o sobrenatural que inquieta o leitor com a possibilidade do irreal tornar-se real.

A narrativa fantástica se configura a partir dessa possibilidade do irreal tornar-se real. A conflagração na narrativa de acontecimentos aparentemente inexplicáveis e imprecisos, que fuja às leis lógicas da nossa realidade posta gera um sentimento de hesitação que permite o narrador, 
personagem e leitor duvidar, mesmo por um instante, daquilo que é narrado, questionando-se inclusive sobre a naturalidade e a realidade dos fatos. Mais do que isso, 0 motivo de ser do fantástico é a revelação de algo "que vai transtornar a nossa concepção de realidade" (ROAS, 2014, p.114) através da provocação de uma inquietante incerteza acerca da realidade que nos cerca, bem como da percepção do "eu" como indivíduo socialmente constituído.

Mesmo na sociedade contemporânea, e, talvez, principalmente nela, o homem teme perder o controle de si diante de situações cada vez mais estressantes no seu dia-adia. Deixar vir à tona sua animosidade pode ser desastroso. A vida em sociedade faz com que trancafiemos o lobo que reside dentro de nós. No entanto, quanto mais tempo uma fera fica presa mais força ela ganha para se libertar. E, ao se libertar, pode causar estragos irreparáveis. O medo de que os lobos possam se libertar permite que a personagem do lobisomem, na narrativa contemporânea, corporifique um medo ainda atual.

Do licantropo grego ao Lobinho das histórias em quadrinhos de Maurício de Souza, a lenda do homem que se metamorfoseia em lobo é, talvez, uma das mais antigas lendas lidas e relidas pela literatura, estando muito além dos filmes 
clichês hollywoodianos. A lenda, até onde se pode rastrear, tem origem na mitologia grega e apresenta diversas versões em diferentes culturas, mas em sua maioria a transformação de humano em lupino se dá por causa de um castigo divino àquele que adentrou o campo do proibido, do impenetrável. Ou, simplesmente é fruto de uma predestinação.

N'As Metarmofoses, de Ovídeo, por exemplo, Licaón é castigado por Júpiter por primeiro tentar matá-lo enquanto dormia, e no dia seguinte, ter-lhe servido carne humana com a intenção de testar sua divindade:

Tão logo pôs tais carnes sobre a mesa, eu castigo-o com a chama:

sobre o dono e os penates dignos dele o teto derrubei;

ele, aterrado, foge e, deparado

o silêncio do campo,

ulula e, em vão, esforça-se em falar;

de dentro dele próprio

a boca extrai a raiva, e, com desejo

de morte costumeiro,

é convertido em besta e, ainda agora, regala-se com sangue.

Vão-se em pelos as vestes; vão-se em patas

os braços de Licáon; 
faz-se lobo, e da sua velha forma só vestígios conserva:

do vulto, o mesmo pelo agrisalhado;

é a mesma a violência;

os mesmos são os olhos que reluzem,

a imagem de feroz". (OVÍDEO, Apud CARVALHO, 2010, p.13)

Licaón perde sua humanidade, transforma-se numa fera ávida pelo massacre e pelo sangue, mas ainda conserva vestígios do homem que foi. Observemos o que rezam os últimos versos: "do vulto, o mesmo pelo agrisalhado;/ é a mesma a violência;/os mesmos são os olhos que reluzem, a imagem de feroz". Em outra tradução lê-se: "as mesmas cãs, o mesmo rosto violento/o mesmo olhar brilhante e um furor idêntico" (OVÍDEO, Apud CARVALHO, 2010, p.46), indicando que a fera indomável já vivia em Licaón. O deus do Olimpo apenas permitiu que tais características viessem à tona através da metamorfose reificando seu estado moral anterior: um homem amoral e violento.

A versão da lenda brasileira, em especial a que ronda pelo sul e sudeste do Brasil, relaciona a metamorfose do homem em besta às relações sexuais ignominiosas:

Dizem que eram homens que, havendo tido relações impuras com as comadres, emagreciam; todas as sextas-feiras, alta 
noite, saíam de suas casas transformados em cachorro ou em porco, e mordiam as pessoas que a tais desoras encontravam; estas, por sua vez, ficavam sujeitas a transformarem-se em lobisomens... (NETO, 2002, p.40)

Já outra versão, corrente no nordeste brasileiro, relaciona a metamorfose à predestinação. Diz-se nessa região que o filho nascido após uma sequência de sete filhas, ou o sétimo filho numa sequência de seis meninos certamente virará um lobisomem. ${ }^{1}$

Seja numa ou noutra versão da lenda, aqui ou na Grécia antiga, o lobisomem surge como um monstro engendrado para afirmar e reafirmar o poder da proibição de determinados comportamentos. A persistente descrição da condição monstruosa de Licaón em todo o canto enfatiza isso: o homem não deve adentrar o território proibido sob o risco de ser punido por forças que estão além da sua compreensão.

Assim, todo monstro constitui, e com o lobisomem não é diferente, "uma narrativa dupla, duas histórias vivas: uma que descreve como o monstro pode ser e outra - seu testemunho

\footnotetext{
1 Há ainda outras versões da lenda, conforme apontado pelo estudo de Câmara Cascudo, Geografia dos mitos brasileiros, quer no Brasil, quer em outros territórios. O estudioso rastreia o mito desde as versões latina e romana até seu desmembramento pela Europa e por fim, da Península Ibérica às Américas. Afirma que, ao menos segundo sua pesquisa, não houve um Lobisomem ou lenda parecida na América pré-colombiana, bem como no Brasil pré-cabralino, tendo sido, portanto, as nossas versões da lenda pura herança europeia. (CASCUDO, 2012, p.249-p.279)
} 
que detalha a que uso cultural o monstro serve" (COHEN, 2000, p.23-60). A figura do homem-lobo, portanto, funcionou, tanto na época de Ovídeo como na de Lopes Neto, como um monstro da proibição engendrado para controlar as massas.

Por outro lado, por estar ligado a práticas proibidas, ele torna-se também um objeto de desejo, pois,

\begin{abstract}
as mesmas criaturas que aterrorizam e interditam podem evocar fortes fantasias escapistas; a ligação da monstruosidade com o proibido torna o monstro ainda mais atraente como uma fuga temporária da imposição (COHEN, 2000, p.23-60)
\end{abstract}

o que nos faz perceber que precisamos do monstro. E é essa relação de repulsão e atração que confere ao lobisomem uma popularidade cultural que perpassa os anos.

\title{
UMA (RE)LEITURA CONTEMPORÂNEA
}

$\mathrm{Na}$ introdução desse artigo falamos que os medos podem perpassar épocas e culturas permitindo que seus monstros sobrevivam para nascer e renascer outra vez, em outras épocas. Trata-se, entretanto, de algo mais do que isso. É que, como já afirmara Umberto Eco (2003), os personagens migram. E migram de história em história, de texto em texto, de época em época. $E$, a cada renascimento uma nova (re)leitura se engendra. E de (re)leitura em (re)leitura o monstro, tal qual personagem, vai 
ganhando novas formas, metamorfoseando-se para se adequar às novas sociedades e aos seus velhos medos.

Independente da época, da sociedade ou da cultura em que o sujeito esteja imerso, o homem teme e sempre temeu o monstro que vive dentro de si e que pode vir a lume na próxima lua cheia. Ademais, mesmo que o monstro não seja eu, o fato de saber que "ele mora [ou pode morar] no nosso meio" (COHEN, 2000, p.23-60), inquieta e amedronta. O lobisomem pode muito bem ser cada um de nós; sedutor ou animalesco, ele vive dentro de nós.

É justamente a partir dessa fissura que jaz em todo ser humano - uma fissura que pode deixar escapar seu monstroque o fantástico surge em Rubens Figueiredo. O autor carioca resgata, reconstrói e remodela a lenda do lobisomem para mostrar que cada um de nós pode libertar a fera adormecida dentro de si. Para tal ele recorta trecho d'As Metamorfoses, de Ovídio, da Bíblia, da República, de Platão e outros textos para falar de seu lobo, ou melhor, do seu lobisomem, Simão.

Simão é um rapaz de gênio indomável que foi deixado, ainda menino, aos oito anos, em um mosteiro - a Casa - por seus pais. E será através de uma narrativa entrecortada, tenta narrar sua história, ou melhor o momento estopim de sua metamorfose de homem em 
lobo. Sua narrativa oscila entre dois momentos narrativos: passado, quando ainda homem e; presente, momento em que a metamorfose transcorre e que coincide com o ato de escritura da narrativa.

Vegetariano, como todos que viviam no colégio-mosteiro, nunca havia provado carne. Quando Estevão alimentava o casal de lobos-guará - "criaturas destituídas de qualquer maldade" (FIGUEIREDO, 2009, p.49) - que todas as noites iam visitá-los, num ritual que durava mais de dez anos, até mesmo o cheiro do alimento lhe incomodava. Mas a convivência com Raquel; o desejo por ela; o convívio com os lobos; as visitas às cavernas, primeiro com Gregório, o bibliotecário e seu mestre, depois com Raquel, a espeleóloga, foram paulatinamente transformando a repulsão em desejo.

Após o que se pode chamar de uma relação sexual voluptuosa, primitiva e selvagem com Raquel, ele acorda sozinho na floresta e retorna para casa. Decide entrar pela segunda cozinha, a dos carnívoros (que servia os visitantes como Raquel) e como um bicho vasculha tudo a procura de carne:

Entrei pela porta meio aberta. Vi sangue sobre uma pequena prancha de madeira. Facas, facões tingidos de vermelho. Jogados em um latão de metal, ossos, pelanca, fibras brancas, tripas de galinha 
[...]. Num instante a cozinha me engoliu inteiro: estava à minha espera, a presa de que ela se alimenta. Logo encontrei o que queria e não me importei com que a carne estivesse crua. $O$ contato gelado e mole na mão. Corri de volta para a floresta, enquanto a ponta do pedaço de carne balançava com os movimentos do meu braço. Eu segurava com força, os dedos se enterravam naquela massa, em que senti a moleza do barro e a resistência dos fios trançados de um pano grosso [...]. Lembrei de ter chegado o pedaço de carne bem perto do rosto, dos olhos, e lembrei ter cravado depois os dentes com força, e arrancava pedaços que precisavam ser partidos de novo para que coubessem na boca. Lembrei como a carne se defendia, não queria se desfazer sob minhas dentadas. Senti as fibras se soltarem aos poucos, enquanto algumas se enfiavam no intervalo dos dentes. [...] Por dentro, o organismo reagia, queria rejeitar, expelir [...]. Eu sufocava um pouco, arfava e gemia sem perceber. Eu queria, e meu estômago não. (FIGUEIREDO, 2009, p.49)

Ele já não era mais o mesmo. A fera que residia dentro de Simão, manifestava-se. O então sacerdote cometia dois crimes a relação sexual e o consumo de carne. Note que ambos acontecem a um só momento como se as duas atividades estivessem correlacionadas. E estavam: o sexo como um desejo da carne e a carne como um desejo da alma. 
Mas o narrador valoriza mais o consumo da carne do que a relação sexual, pois, a este dedica apenas um parágrafo, àquela, duas páginas inteiras. Aliás, Simão é tão descritivo em relação à carne como quando descreve Raquel, seu cabelo, seu corpo, seus gostos e gestos. Ela é a carne, o seu pecado e a chave para a sua metamorfose!

Assim como Licaón metamorfoseia-se em lobo dando origem a um monstro que cumpre afirmar e reafirmar o poder da proibição de determinados comportamentos, assim é o lobo Simão que, se não reafirma o poder da proibição social e religiosa, no mínimo o questiona.

Após esse episódio, Simão encontra um trecho d'A República que aludia a uma certa fábula a respeito do templo de Zeus Lícaios. A partir dessa leitura começa a juntar as peças de um engendrado quebra-cabeças que revelaria a sua verdadeira natureza.

O bibliotecário Gregório, desde que solicitou que o menino rebelde ficasse sob sua supervisão, cuidou de ensinar-lhe tudo sobre os livros, sobre as montanhas e as cavernas da floresta das quais era exímio conhecedor. Quando Simão era ainda muito jovem e com pouca leitura pedia à senhora que cuidava da horta para contar-lhe algumas histórias. Mais tarde passou a separar trechos para 
sua leitura; em outros momentos, Gregório levava Simão para desbravar a mata da região, inclusive suas cavernas.

As lições do bibliotecário, enfim, pretendiam, ou alertar Simão da fera que carregava em si, ou ensinar-lhe a lidar com ela. Em um dos trechos que reservara para a leitura do jovem Simão

estava escrito que na Grécia antiga havia uma lenda sobre os lobos, uma crença também encontrada em outros países e em épocas diferentes: à noite, se um lobo olhasse para os olhos de um homem antes que ele tivesse visto o lobo, o homem ficaria mudo. (FIGUEIREDO, 2009, p.35)

Gregório era mudo. Teria ele olhado nos olhos dos lobos da região? Se sim ou não o narrador não diz, mas como prossegue, se "tivesse virado a página, veria que outra versão da lenda dizia que o homem se transformaria em lobo. "Mas só virei essa página mais tarde" (FIGUEIREDO, 2009, p.35), diz ele. Teria também Simão olhado nos olhos dos lobos? Ou sua metamorfose era fruto de uma predestinação? A relação entre ele e os canídeos era bastante próxima, muito mais do que a de Estevão que só os alimentava. Mas sempre teve o cuidado de não os encarar, de não olhar em seus olhos; cuidado que passou à Raquel quando levou-a até os animais na parte do jardim onde iniciava a floresta: "Não 
olhe nos olhos deles", ele dizia, "não olhe nos olhos deles" (FIGUEIREDO, 2009, p.41).

Talvez o jovem pudesse ter percebido tudo antes e de alguma forma ter evitado a morte de Raquel. Mas não, ele não virou a página, não terminou a leitura indicada pelo seu mestre. A página só foi virada muito tempo depois da morte de Gregório, quando a metamorfose já estava no seu auge.

Não demorou muito para que Simão percebesse que Gregório ainda tinha muito a lhe dizer. Antes de sua morte, o bibliotecário deixou algumas páginas marcadas para sua leitura e um pedido de que Simão o substituísse na biblioteca. Ao se dar conta disso, das marcações, começou a caçar as passagens literárias, peças de seu quebra-cabeça. Foi então que começou a compreender o que lhe acontecia. "Gregório me mostrava o caminho. [...] Era estranho, mas Gregório me mostrava a direção. As histórias formavam elos. As montanhas, as cavernas, a carne, eu também era um elo" (FIGUEIREDO, 2009, p.50).

A montanha que sob determinado ângulo parecia representar a parte superior de seu rosto humano, sob outro ângulo mostrava um lobo deitado; as cavernas que Gregório lhe ensinou a mapear com a mente, o desejo pela carne; o desejo por Raquel; suas características de "menino selvagem"; as passagens 
literárias. Sim, tudo era um elo! Tudo se encaixava com exatidão e explicava sua natureza não exatamente humana.

Como Gregório podia saber, Simão se questionava, se quando o tomou a sua guarda só tinha nove anos? Se seu tutor soube antecipadamente; o rapaz demorou a desvendar o mistério. Quando compreendeu, já era tarde. A fera já havia se manifestado, ao menos internamente, e em breve faria sua primeira vítima; Raquel não completaria o seu estudo sobre as cavernas da região, mas faria de uma delas seu túmulo.

[...] Apesar da confusão com o sumiço de Raquel, os lobos vieram e Estevão Ihes deu o que comer. Os lobos vieram ao meu encontro e juntos para o interior da Floresta. O silêncio dos nossos pés era um só. Roçando nas pedras do chão, na terra seca ou lamacenta, minhas mãos e meus pés eram também, os quatro uma coisa só. (FIGUEIREDO, 2009, p.58)

É já um lobo, a metamorfose externa estava em curso. Mas mesmo que a fera o dominasse ainda conservava sua consciência humana.

Os relatos da transformação de um ser em outro só se concluem com a transformação da voz. Isso se dá principalmente quando se trata da transformação de um ser humano em animal ou árvore. Um dos momentos cruciais do processo é a descrição da transformação da voz humana em 
voz de animal ou a descrição da perda dessa faculdade em função da perda da identidade anterior e a passagem para o reino vegetal ou mineral. 0 detalhe trágico é que à transformação corporal não se segue uma transformação na consciência do ser transformado. Transformados em animais ou árvores, os antigos seres humanos permanecem mentalmente humanos! E é justamente a percepção da mudança da voz o sinal que evidencia a mudança de estado. (CARVALHO, 2010, p.6)

Assim como Licaón, Simão tem consciência de sua metamorfose, tanto, que tenta em vão escrever suas memórias de forma a perpetuar sua humanidade. "Enquanto escuta o seu uivo ecoando no silêncio dos campos, Licáon tenta em vão recuperar a fala" (CARVALHO, 2010, p.7) e Simão escreve seu diário e confissão. Sua voz já não é mais humana, suas mãos cheias de garras rasgam as páginas do caderno. Segura a caneta com a boca e tenta escrever como pode, numa tentativa de manutenção da sua humanidade, mas "as canetas de plástico se destroem cada vez mais depressa nos meus dentes, nas minhas mãos embrutecidas." (FIGUEIREDO, 2009, p.35).

Enclausurado na caverna em que morreu a espeleóloga, enquanto todos da Casa procuravam por Raquel, escreve sua história antes que o encontrem, talvez numa tentativa 
de remissão. Mas os latidos dos cães de caça se aproximam rapidamente, o caderno está no seu fim e ele não escreveu tudo o que precisava escrever.

\section{REFERÊNCIAS}

CARVALHO, Raimundo (2010). Metamorfoses em tradução. São Paulo: USP. In http://www.usp.br/verve/coordenadores/raimundocarvalho/rascunhos/ metamorfosesovidio-raimundocarvalho.pdf Acesso em 28.Jul.2014.

CASCUDO, Luís Câmara (2012). Geografia dos Mitos Brasileiros. São Paulo: Editora Global.

COHEN, Jeffrey Jerome et al. (2000). Pedagogia dos monstros; os prazeres e os perigos da confusão de fronteiras. Belo Horizonte: Autêntica.

ECO, Umberto (2003). Sulla Letteratura. Milano: Tascabili Bompiani.

FIGUEIREDO, Rubens (2009). "Alguém dorme nas cavernas". In: O livro dos lobos. São Paulo: Companhia das letras.

JEHA, Júlio (2007). "Monstros: A face do mal". In: JEHA, Julio (Org). Monstros e monstruosidades na literatura. Belo Horizonte: Editora UFMG (2007). "Monstros como metáforas do mal". In: JEHA, Julio (Org). Monstros e monstruosidades na literatura. Belo Horizonte: Editora UFMG. MONTAIGNE, Michel de (1991). Ensaios. São Paulo: Nova Cultural. NETO. João Simão Lopes (2002). Lendas do Sul. Porto Alegre: Artes e Ofícios. RAPUCCI, Cleide Antonia (2012). "Mulheres e lobas: a transposição de fronteiras na obra de Angela Carter". In: VOLOBUEF, Karin et al (Orgs.). Vertentes do fantástico na literatura.. São Paulo: Annablume.

ROAS, David (2012). "Mutaciones pós-modernas: del vampiro depredador a la naturalizacíon del monstruo". In: Revista Letras \& Letras Uberlândia, 28(2). (2014). A ameaça do fantástico: Aproximações teóricas. São Paulo: Editora UNESP.

OVÍDEO, Publio (2010). "A metamorfose de Licaón". In: Metarmofoses: antologia de contos. São Paulo: Cia das letras. 
Karla Menezes Lopes Niels- Possui graduação em Letras - habilitação português/italiano pela Universidade do Estado do Rio de Janeiro (2010) e mestrado em Literatura Brasileira pela Universidade do Estado do Rio de Janeiro (2013). Doutoranda em Estudos da Literatura da Universidade Federal Fluminense, com previsão de defesa para o primeiro semestre de 2018. Atualmente atua como professora de língua portuguesa e literatura na rede Estadual do Estado do Rio de Janeiro, na unidade escolar C.A.I.C Theóphilo de Souza Pinto e como professora substituta no Cefet-RJ, campus Maria da Graça. Pesquisa principalmente os seguintes temas: literatura fantástica, romantismo brasileiro e recepção da narrativa.

Recebido em 01 de maio de 2016 Aprovado em 25 de maio de 2016 